\title{
Effects of Somatosensory Training on Upper Limb for Postural Control and Locomotion in Hemiplegic Stroke with Unilateral Neglect
}

\author{
Bo-Kyoung Song \\ Department of Occupational Therapy, College of Health Science, Kangwon National University, Chuncheon, Korea
}

\begin{abstract}
Purpose: The purpose of this study was to examine the effect of postural control and locomotion on improvement of two point discrimination (TPD), stereognosis (ST) through somatosensory training (SST) on the upper limb (UL).

Methods: The subjects were 20 hemiplegia patients who have problems with unilateral neglect after stroke. The patients were divided into two groups, the experimental group (EG) and the control group (CG). In the EG, SST for TPD, ST was performed 18 times, three times a week for six weeks, together with physical therapy (PT) and occupational therapy (OT). In the CG conventional PT and OT without SST was performed for six weeks. Several assessment tools were used in comparison of groups; two point discrimination test (TPDT) on fore$\operatorname{arm}(\mathrm{F})$, thenar (T), hypothenar (TH), thumb tip (TH-T), index finger tip (IN-T), stereognosis test (ST), postural assessment scale for stroke (PASS), and clinical test of sensory interaction on balance (CTSIB) and timed up and go test (TUG).

Results: In the CG, conventional PT and OT resulted in statistically improved TPDT (F), ST, PASS, and TUG. In the EG, SST resulted in statistically improved TPDT (F, T, HT, TH-T, IN-T), ST, PASS, and TUG. TPDT-T, ST, and CTSIB with length of displacement with eye open (LDEO) also showed significant improvement between the groups.

Conclusion: In both groups TPDT ST, PASS and TUG, and SST had effects on the UL and TPDT, ST and static postural control had greater effects compared with the PG. Therefore, we could assume that TPD and ST are very important in performing human activities including postural control and locomotion.
\end{abstract}

Keywords: Stroke, Hemiplegia, Unilateral neglect, Somatosensation, Postural control, Locomotion

\section{서 론}

인간은 선 자세에서의 조절능력을 통하여 두발을 앞으로 부드럽게 이동하는데 이를 인간보행(human locomotion)이라 정의한다. 인간보 행은 다른 포유류에 비해 이동에 필요한 신체 에너지 사용을 최소화 하기 위하여 신체의 움직임을 통합하여 근 활동의 조절과 보행의 효 율성을 증진시킨다. ${ }^{2}$ 그리고 신체 발달 과정의 감각, 지각, 운동 기능 의 통합 및 신체조절의 향상을 통해 보행을 안정적으로 발전시키며 선 자세에서의 무게 중심점의 이동능력, 보행 과정에서 적절한 골반 의 좌우 회전운동, 발목, 다리, 무릎의 움직임, 어깨의 회전 움직임을 통하여 보행의 효율성을 증진시킨다.,2 따라서 안정적이고 효율적인 보행을 위하여 역동적인 조절능력과 외부환경의 적응능력 등이 요 구된다. 중력에 대항하여 신체를 조절하는 능력뿐만 아니라 예상하

Received Sep 16, 2015 Revised Oct 15, 2015

Accepted Oct 19, 2015

Corresponding author Bo-Kyoung Song

E-mail bksong@kangwon.ac.kr
지 못한 외부적인 힘으로부터 적절하게 반응하여 신체를 조절하는 능력을 역동적인 자세조절 능력이라 하는데 이는 선 자세, 보행의 시 작, 보행 과정에 중요한 요소로 작용한다. 그리고 보행 과정에서 다양 한 장애물에 대한 대처능력은 각 개인에게 요구되는 능력으로 장애 물 특성에 따라 보행속도, 방향 및 보행패턴을 수정하는 데 도움을 준다. 따라서 체감각, 지각을 통한 공간인식능력, 자세조절 및 문제해 결능력은 독립적이고 효율적인 보행을 수행하는데 매우 중요하다.1

뇌졸중 후 편마비 환자는 자세유지근 및 수의근의 약화, 감각인식 및 해석의 어려움, 언어장애, 자세 조절 및 인지기능의 저하로 정상인 에 비해 비효율적이며 의존적인 자세조절과 보행을 수행한다. 특히 실시간 입력되는 감각정보의 인식과 해석의 어려움은 신체인식력에 부정적인 영향을 주어 자세안정성, 보행의 시작, 입각기 및 유각기 등 에서 어려움을 발생한다. 그리고 자세 유지근의 약화는 선 자세와 같 
은 항중력 자세를 지속적으로 유지하거나 효율적인 근 수축을 동원 하는데 어려움을 준다. 이러한 자세 유지근의 약화는 1차적으로 고유 감각의 인식능력 저하로 적절한 근수축과 운동패턴을 생성하지 못한 다. 따라서 뇌졸중 후 편마비 환자의 기능적인 자세조절과 독립적이 고 효율적인 보행장애는 거시적으로 나타나는 근약화의 문제뿐만 아 니라 감각정보를 적절하게 인식하고 해석하지 못하여 발생하는 복합 적인 기능활동장애로 인식하여야 한다. 특히 편측무시를 동반한 편 마비 환자는 공간인식 및 주의력 손상을 동반하여 운동기능을 손상 받은 환자에 비해자세조절 및 보행에 더 큰 어려움을 가지게 된다.

편측무시는 대뇌피질의 여러 부위 중 오른쪽 하두정엽 손상에서 가장 흔하게 나타나며 오른쪽 전두엽, 시상과 기저핵의 손상에도 나 타난다. ${ }^{5}$ 일반적으로 편측무시는 왼쪽 대뇌 반구 손상에서는 거의 나 타나지 않으며 오른쪽 대뇌 반구 손상에서 나타난다. ${ }^{6}$ 최근 신체인식 력(body schema)의 손상으로 인하여 편측무시가 발생한다는 신경가 설을 근거로 임상에서 많은 치료접근이 이루어지고 있다. 신체인식력 은 체감각 정보의 통합을 통하여 신체 각 부위의 상태와 움직임 및 외부환경을 적절하게 인식하고 신체동작을 적절하게 구성하는 신경 요소로 작용하며 일상생활활동과 같은 신체활동과 연관된 기능활 동을 수행하는 데 기여하는데 신체인식력의 손상과 연관된 편측무 시 환자는 공간이동, 옷 입기 및 위생 활동 등의 일상생활 활동에 부 정적인 영향을 미칠 수 있다. 최근 뇌졸중 후 편마비 환자의 편측무 시를 개선하기 위한 치료방법으로 시각 및 체감각 자극을 이용하였 는데 이는 위쪽 경로(dorsal stream pathway)을 통해 목표물을 설정하 여 이를 동작에 연결하고 체감각수용기의 지배밀집도가 많은 손, 어 깨 및 목 부위에 체감각 자극 훈련을 통하여 공간인식을 회복하는데 긍정적인 효과를 확인할 수 있었다. ${ }^{89}$

특히 손을 포함하는 상지의 체감각 훈련은 발달된 체감각 수용기 를 통하여 체감각 피질까지 정보를 전달하고 연합피질 영역의 다양 한 수평 신호분석 체계를 통하여 신체인식 및 자세 조절에 관련한 정 보를 제공하는데 효과적인 도움을 줄 수 있다. ${ }^{10}$ 하지만 뇌졸중 후 편 측무시를 동반한 편마비 환자의 상지 체감각 훈련을 통한 보행과 자 세조절의 변화를 보고한 연구가 충분하지 않았다. 이에 본 연구는 편 측무시를 동반한 편마비 환자의 상지 체감각 훈련과 기존치료가 자 세조절과 보행에 어떠한 영향을 주는지 알아보고 자세조절과 인간보 행의 치료접근과 근거를 모색하고자 한다.

\section{연구 방법}

\section{1. 연구 대상}

본 연구는 경기도에 위치한 재활병원에 입원중인 편측무시를 동반한 편마비 환자 중 연구 목적, 치료내용 및 방법에 동의한 20 명의 환자를
대상으로 실시하였다. 선정 기준은 신경과 및 재활의학과 전문의로부 터 뇌졸중으로 인한 편측무시와 편마비를 동시에 진단을 받은 대상 자 중 편측무시 선별검사인 알버트 검사(albert test, AT)에서 선의 편위 가 있고 별지우기검사(star cancellation test, SCT)에서 왼쪽의 지운 개 수와 전체 지운 개수를 통해 왼쪽의 편측무시를 나타내는 자, 발병일 이 3 개월에서 12 개월 사이로 다시 재발하지 않은 자, 나이가 만 65 세 이하인 자, 혼자서 앉기나 보행이 가능한 자, 뇌졸중 진단 외에 외과질 환, 시각장애 및 다른 질환이 없는 자, 한국형 간이 정신 상태 판별검 사(Korea version Mini Mental State Examination, K-MMSE) 점수가 21점 에서 26점의 경도 이상인 환자를 대상으로 진행하였다.

\section{2. 측정 도구}

1) 두점구별 검사(two point discrimination test, TPDT) 두점구별 검사는 Dellon Disk-Criminator 2 Point (Sammons Preston, USA)도구를 사용하였다. 두점구별 검사는 인지 가능한 두점자극의 최소거리를 측정하여 자극의 특성을 구별하는 검사방법으로 두점 사이의 거리를 점차 줄여 두 점이 한 점으로 느끼기 전까지의 거리를 측정한다. 개인의 차이가 있지만 정상범위는 혀 $1 \mathrm{~mm}$, 손끝 $2-5 \mathrm{~mm}$, 손바닥 8-12 mm 등 부위에 따라 400-600 mm 이내의 거리를 인식하 면 정상이다." 본 연구에서는 아래팔(forearm, TPDT-F), $100 \mathrm{~mm}$ 엄지 두덩(thenar eminence, TPDT-T), 작은두덩(hypothenar eminence, TPDT-HT), 부위 $20 \mathrm{~mm}$, 엄지손가락끝(thumb tip, TPDT-TH-T)과 검지 손가락끝(index finger tip, TPDT-IN-T) $10 \mathrm{~mm}$ 를 기준으로 검사하였 다. 본 검사는 앉은 자세에서 조용하고 산만하지 않은 공간에서 검사 자나 검사 도구로부터 소음을 최소화하였다. 대상자의 마비측 측정 부위를 노출하여 검사하였고 검사하는 동안 대상자의 시각은 차단 하도록 하였다. 검사자는 대상자의 접촉부위가 한 점, 또는 두 점인지 느끼는 대로 말하도록 하고 검사과정에서 감각자극에게 대한 피드 백을 주지 않았다. 검사자는 대상자가 두점을 인식하지 못하는 범위 까지 검사를 진행하고 손에서는 $1 \mathrm{~mm}$, 아래팔에서는 $2 \mathrm{~mm}$ 씩 수정 하여 검사 범위를 수정하여 검사하였다. ${ }^{2}$

2) 입체인식 검사(stereognosis test, ST)

입체인식 검사는 연필, 동전 등 일상에서 쉽게 사용되는 17 개의 물건 과 17 개의 물건을 그려놓은 카드로 구성된 Stereognosis Kit (Sammons Preston, USA)을 사용하였다. 환자는 손의 촉각을 통해 17 개의 서로 다른 물건을 인식 여부를 접촉 매칭 방법을 사용하여 검사하였다. ${ }^{12}$

3) 감각상호작용 및 수정 균형 검사(clinical test of sensory interaction on balance, CTSIB)

본 검사는 정량 평가가 가능한 force platform system (model OR6-7- 
2000, Advanced Mechanical Techn Inc., USA)을 사용하였다. 검사자는 힘판 위에서 두 발을 평형하게 올려놓은 후 선 자세에서 눈을 뜬 상태 (length of displacement with eye open, $\mathrm{LDEO}$ )와 눈을 감은 상태(length of displacement with eye closed, LDEC)에서 10초를 측정하였고 이어서 $5 \mathrm{~cm}$ 높이의 스펀지로 제작된 부드러운 지지면(foam surface) 매트 위 에 서게 한 후 같은 방법으로 눈을 뜬 상태(length of displacement with foam surface and eye open, LDFSEO)와 감은 상태(length of displacement with foam surface and eye close, LDFSEC)에서 10초간 측정하였고 무게 중심점의 이동 거리에 대한 평균을 구하였다.13

\section{4) 뇌졸중 자세 평가 척도(Postural Assessment Scale for Stroke, PASS)}

본 검사는 Fugl-Meyer 균형 척도 항목을 수정 보안하여 뇌졸중 환자 의 정적, 동적인 자세조절 능력을 평가하기 위해 제작된 도구로 뇌졸 중과 같은 뇌손상 환자에게 적용 가능한 난이도의 평가 항목으로 구 성되어 자세조절능력을 쉽게 평가할 수 있어 임상에서도 유용하게 사용되는 평가척도이다. PASS는 자세 유지 5항목과 자세 변환 7항목, 총 12 항목으로 구성되었고 점수는 항목당 최소 0 점에서 최고 3 점을 적용하여 0 점에서 최대 36 점으로 측정할 수 있다. 본 검사의 타당성 과 신뢰도 사전연구에서 FIM과의 상관관계에서 높은 구성 타당도 $(\mathrm{r}=0.73)$ 와 검사자 간 신뢰도 $(\kappa=0.88)$, 검사 재검사 신뢰도 $(\kappa=0.72)$ 를 보였다. ${ }^{14}$

\section{5) Timed "Up and Go" Test (TUG)}

본 검사는 노인의 자세조절력과 기능적인 보행능력을 평가하여 낙상 의 위험을 예측하기 위하여 사용되었으며 최근에는 허약한 노인뿐 만 아니라 뇌졸중, 파킨슨병, 관절염 환자에게도 적용하였다. ${ }^{15,16}$ 측정 방법은 $46 \mathrm{~cm}$ 높이의 팔걸이가 있는 의자에 앉은 자세에서 일어나 3 $\mathrm{m}$ 를 왕복하여 걸은 뒤, 원위치로 돌아와 앉는 데 소요되는 시간을 측정하였다. 본 연구에서는 검사 전후 동일한 보행 조건에서 타인의 도움 없이 검사를 시행하였고 전자 타이머를 이용하여 2회를 측정한 후 평균시간을 산출하였다. 본 검사는 검사자 간 신뢰도가 $\mathrm{r}=0.98$, 검 사자 내 신뢰도는 $r=0.99$ 로 높은 신뢰도를 보였으며 보행속도와 버그 균형 척도와도 상관성을 갖는다고 보고하였다.15

\section{3. 연구 방법}

본 연구는 20 명의 대상자를 보존적 치료군과 체감각 치료군으로 분 류하여 두 치료군 모두에게 진행되는 치료 내용과 방법을 설명한 후 에 주 5 회의 물리치료와 작업치료를 6 주간 동일하게 실시하였고 체 감각 치료군에게는 상지 체감각 훈련을 주 3 회 40 분간 총 6주간의 치 료를 추가 실시하였다. 그리고 치료 전후의 두점구별, 편측무시, 자세
조절능력 및 보행의 차이를 비교 분석하였다. 상지 체감각 훈련은 $\operatorname{Song}^{17}$ 의 연구에서 적용한 방법을 보완하여 어깨와 손 부위에 적용하 였다. 먼저 어깨 부위는 보조-능동운동 및 능동운동을 기반으로 어 깨 복합체 주위 근육의 고유감각을 촉진하였는데 주로 어깨 회전근, 어깨 세모근, 위팔 두갈래근, 위팔 세갈래근 등의 고유감각 증진과 어 깨주위 근육의 안정 가동성을 활성화하였다. 손 부위는 뇌졸중으로 인하여 나타나는 짧아진 손바닥의 외재근의 길이를 정상인과 동일 하게 신장시킨 후 어깨부위와 동일하게 보조-능동운동 및 능동운동 을 기반으로 손 모양을 만들고 잡는 힘을 생성하는데 중요한 역할을 담당하는 벌레근, 새끼손가락의 벌림근, 둘째손가락 동작에 필요한 첫째 뼈사이근 등의 내재근을 활성화하여 손의 모양이 기능적으로 작용할 수 있도록 손허리뼈 관절을 굴힘 방향으로 작용하여 고유감 각을 촉진하였다. 그리고 손바닥과 손가락 끝 부위의 촉각을 자극하 였는데 치료자극은 접촉감지, 접촉구별, 접촉인식(stereognosis) 능력 이 향상되도록 훈련하였다.

\section{4. 통계처리}

본 연구에 참여한 대상자의 일반적인 특성 및 두 치료군의 검사항목 에 대한 평균값과 표준편차를 알아보고자 기술 통계 및 빈도분석을 시행하였다. 그리고 두 치료군의 두점구별, 입체인식, 자세조절 및 보 행 능력에 대한 전 후 비교는 윌콜슨 짝찟기 부호순위검정(Wilcoxon matching-pairs signed-ranks test)을 실시하였고 두 치료군 간의 두점구 별, 입체인식, 자세조절 및 보행 능력의 차이를 알아보기 위하여 만휘트니 검정(Mann-Whitney U-test)을 실시하였다. 분석은 SPSS 17.0 통 계 프로그램을 사용하였으며 모든 자료 처리의 유의수준은 0.05 으로 검정하였다.

\section{결 과}

\section{1. 연구 대상자의 일반적 특성}

본 연구에 참여한 뇌졸중 후 편측무시를 동반한 편마비 환자는 총 20 명으로 성별은 남자 7명(35\%), 여자 13명(65\%)으로 평균 연령은 54.4 세, 평균 체중은 $60.5 \mathrm{~kg}$, 평균 신장은 163.4 명, 평균 유병 기간은 10.5 개 월, K-MMSE 평균점수는 26.8점이었다. 환자의 마비측은 20 명의 환자 모두가 왼쪽이었다. 발병 원인으로 뇌경색은 9명으로 오른쪽 중대뇌 동맥 경색 6 명, 오른쪽 기저핵 경색 1 명, 시상경색 1 명, 측두엽 및 후두 엽 경색 1 명이며 뇌출혈은 11 명으로 전두엽두정엽 출혈 2 명, 측두엽 출혈 1 명, 기저핵 출혈 2 명, 중대뇌동맥동맥류 출혈 2명, 전두엽두정엽 부위의 지주막하 출혈 2명, 시상부위 출혈 2명이었다. 그리고 두 치료 군의 일반적인 특성은 Table 1과 같다. 


\section{2. 두 치료군 치료 전후의 TPDT, ST, PASS, CTSIB 및 TUG의 변화}

Table 2와 같이, 체감각 훈련군에서는 모든 검사 부위의 TPDT와 ST, PASS 및 TUG 검사에서 치료 전후 유의한 차이가 있었으며 $(\mathrm{p}<0.00$,

Table 1. General characteristics of subjects

\begin{tabular}{llcc}
\hline Variable & & EG $(n=10)$ & CG $(n=10)$ \\
\hline Age (year) & $52.6 \pm 12.7$ & $56.2 \pm 10.5$ \\
Weight (kg) & $60.2 \pm 6.5$ & $60.7 \pm 5.7$ \\
Duration (month) & $10.3 \pm 6.3$ & $10.6 \pm 2.1$ \\
height (cm) & & $164.2 \pm 6.3$ & $162.5 \pm 7.1$ \\
Type & Infarction & 4 & 5 \\
Paretic side & Hemorrhage & 6 & 5 \\
& Right & 0 & 0 \\
Gender & Left & 10 & 10 \\
& Male & 4 & 3 \\
K-MMSE & Female & 6 & 7 \\
\hline
\end{tabular}

Values are presented as mean \pm standard deviation.

EG: Experimental group, CG: Control group, K-MMSE: Korea version mini mental state examination. $\mathrm{p}<0.01)$ 보존적 치료군에서는 아래팔 부위의 TPDT와 ST, PASS 및 TUG 검사에서 치료 전후 유의한 차이를 보였다 $(\mathrm{p}<0.01, \mathrm{p}<0.05)(\mathrm{Ta}-$ ble 2).

\section{3. 보존적 치료군과 체감각 치료군 간의 치료 전후 TPDT, ST, PASS, CTSIB 및 TUG의 변화}

Table 3 과 같이 체감각 치료군과 보존적 치료군 사이에서는 치료전 후 엄지부위의 TPDT, ST 및 CTSIB 중 LDEO 항목에서 유의한 차이 를 보였다 $(\mathrm{p}<0.01, \mathrm{p}<0.05)$ (Table 3).

\section{고 찰}

본 연구는 공간인식의 어려움을 갖는 편측무시를 동반한 편마비 환 자에게 적용한 상지 체감각 훈련이 자세조절과 보행에 어떠한 도움 이 되는지 알아보았는데 특히 보존적 치료군과 체감각 훈련군 사이 에 어떠한 차이를 보이는지 알아보고자 하였다. 이를 통해 편측무시 를 동반하는 편마비 환자의 감각증진, 자세조절 및 보행에서 감각치

Table 2. Comparison of the TPDT, ST, CTSIB, and TUG within EG and CG

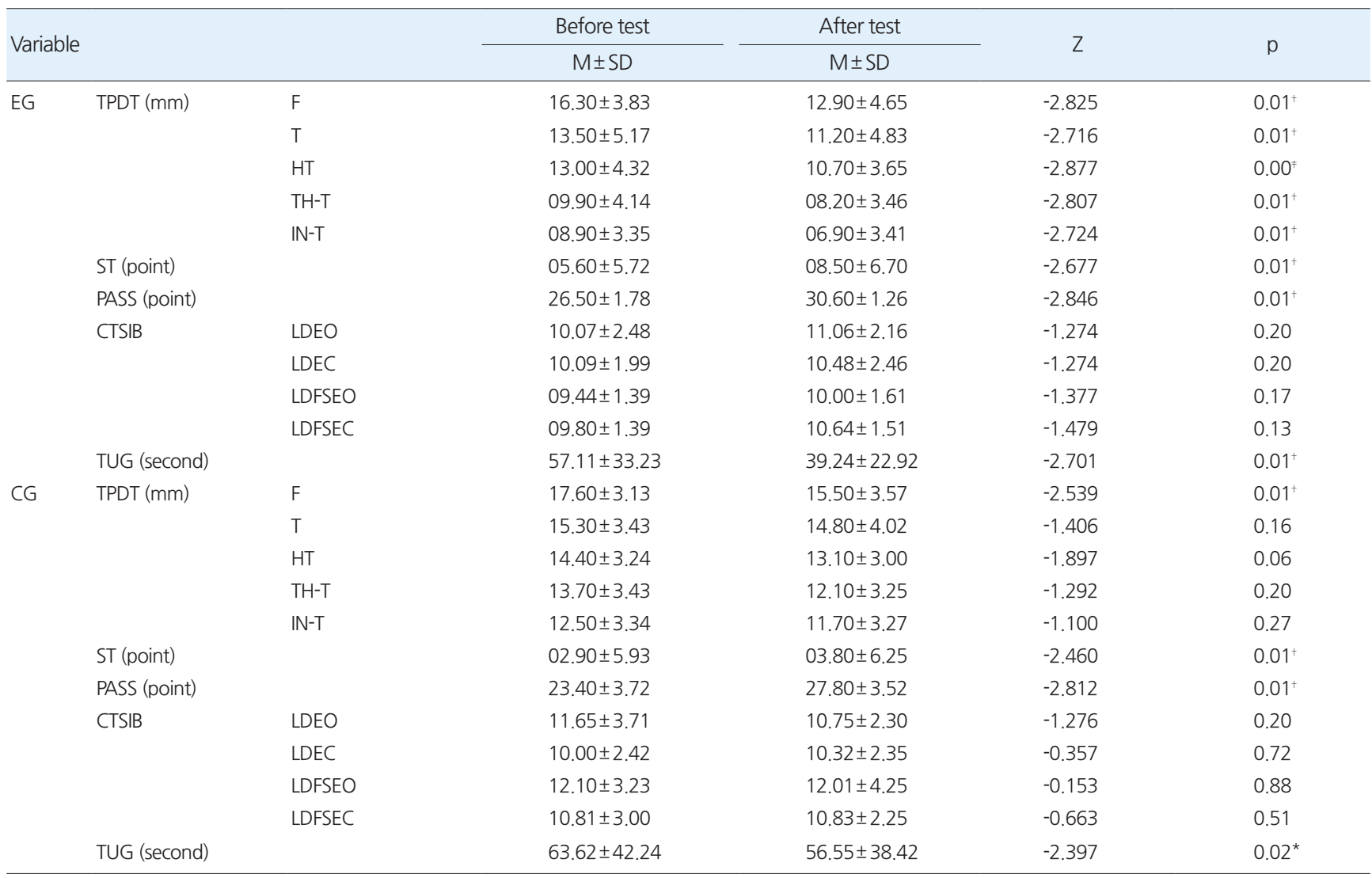

Values are presented as mean \pm standard deviation.

EG: Experimental group, CG: Control group, TPDT: Two point discrimination test, F: Forearm, T: Thenar eminence, HT: Hypothenar eminence, TH-T: Thumb tip, IN-T: Index finger tip, ST: Stereognosis test, PASS: Postural assessment scale for stroke, CTSIB: Clinical test of sensory interaction on balance, LDEO: Lengthofdisplacementwitheyeopen, LDEC: Length of displacement with eye closed, LDFSEO: Length of displacement with foam surface and eye open, LDFSEC: Length of displacement with foam surface and eye close, TUG: Timed up and go test.

${ }^{*} p<0.00,{ }^{+} p<0.01,{ }^{*} p<0.05$. 
Table 3. Comparison of TPDT, ST, CTSIB, and TUG between EG and CG

\begin{tabular}{llcccc}
\hline Variable & & $\mathrm{EG}$ & $\mathrm{CG}$ & $\mathrm{z}$ & $\mathrm{p}$ \\
\hline TPDT & $\mathrm{F}$ & $-3.40 \pm 2.55$ & $-2.10 \pm 1.85$ & -1.276 & 0.20 \\
& $\mathrm{~T}$ & $-2.30 \pm 2.16$ & $-0.50 \pm 1.08$ & -2.463 & $0.02^{*}$ \\
& HT & $-2.30 \pm 2.06$ & $-1.30 \pm 1.95$ & -1.457 & 0.17 \\
& TH-T & $-1.70 \pm 2.26$ & $-1.60 \pm 3.66$ & -0.994 & 0.32 \\
& IN-T & $-2.00 \pm 2.54$ & $-0.80 \pm 1.87$ & -1.609 & 0.12 \\
ST & & $2.90 \pm 2.92$ & $0.90 \pm 0.74$ & -2.047 & $0.04^{*}$ \\
PASS & & $4.10 \pm 1.45$ & $4.40 \pm 1.90$ & -0.655 & 0.51 \\
CTSIB & LDEO & $0.94 \pm 2.09$ & $-0.90 \pm 2.02$ & -2.269 & $0.02^{*}$ \\
& LDEC & $0.39 \pm 1.53$ & $0.33 \pm 1.53$ & -0.303 & 0.76 \\
& LDFSEO & $0.55 \pm 1.34$ & $-0.06 \pm 3.40$ & -0.908 & 0.36 \\
& LDFSEC & $0.86 \pm 1.56$ & $0.02 \pm 1.85$ & -1.059 & 0.29 \\
TUG & & $-17.87 \pm 15.95$ & $-7.08 \pm 8.16$ & -1.475 & 0.14 \\
\hline
\end{tabular}

Values are presented as mean \pm standard deviation.

TPDT: Two point discrimination test, F: Forearm, T: Thenar eminence, HT: Hypothenar eminence, TH-T: Thumb tip, IN-T: Index finger tip, ST: Stereognosis test, PASS: Postural assessment scale for stroke, CTSIB: Clinical test of sensory interaction on balance, LDEO: Length of displacement with eye open, LDEC: Length of displacement with eye closed, LDFSEO: Length of displacement with foam surface and eye open, LDFSEC: Length of displacement with foam surface and eye close, TUG: Timed up and go test. ${ }^{*} \mathrm{p}<0.05$.

료접근의 상관성을 제시하고자 하였다.

인간의 선 자세 및 한쪽 하지로 체중을 이동하는 조절능력은 앉아 서 일어나기, 선 자세에서 앞으로 걷기 등의 기본적인 기능 활동을 수 행하는데 필수 요소로 작용한다. ${ }^{18}$ 하지만 뇌졸중 후 편마비 환자는 감각 및 운동 기능의 손상으로 자세조절 및 보행능력이 저하되며, ${ }^{19}$ 편측무시를 동반한 편마비 환자의 경우, 공간인식의 어려움으로 선 자세에서 손상 측으로 체중을 이동하기가 어려워 독립보행을 수행하 기 어려워진다. ${ }^{20}$

뇌졸중 후 편측무시를 발생하는 원인을 크게 세 가지 신경인지모 델로 설명하는데, ${ }^{21}$ 첫째 각성에 관여하는 도파민 수용체가 오른쪽 대뇌 반구에 비대칭적으로 우세하여 왼쪽 공간에 더 많은 집중력을 가지며 만약 오른쪽 피질하와 피질 구조가 손상되면 왼쪽공간에 대 한 집중력과 각성에 중재 역할을 하지 못하여 왼쪽 무시를 보인다는 신경인지모델이다. ${ }^{22,23}$ 둘째로 방향인식과 관련하여 왼쪽에 비해 오 른쪽 대뇌가 집중이동에 우세하게 작용하는데 만약 오른쪽 대뇌가 손상되면 집중이동 기전의 손상으로 인하여 오른쪽 자극을 우선적 으로 감지하여 편측무시가 나타난다는 신경인지모델이다. ${ }^{24}$ 마지막 으로 가장 우세적인 근거로 내적 표현의 결손이 공간의 비대칭적인 할당을 만들어 편측무시를 발생한다는 것으로 내적 표현이란 외부 환경과 신체 각 분절 간의 공간성, 움직임의 정보에 대한 중추신경의 신경망을 의미하는데 이를 다른 용어로 신체인식력이라 한다. 25 신체 인식력은 피부감각, 근육 및 관절감각과 같은 체감각 입력과 통합과 정을 통하여 공간 내 신체위치와 움직임을 인식하며 신체 각 분절 간
의 관계를 인식하는 기초신경정보이다. 따라서 신체인식력은 공간인 식, 신체동작의 시작과 과정에도 연관되며 외부 환경을 지각하여 신 체활동을 하는데 기초가 된다. 이를 토대로 제시된 신체인식력의 증 진방법으로 체감각의 효과적인 자극과 능동적으로 신체를 조절하도 록 감각정보를 집중화, 기능화하는 것이다. ${ }^{26}$ Robert 과 North ${ }^{27}$ 는 뇌졸 중 후 편측무시를 동반한 편마비 환자의 손상된 손과 발에 수동, 능 동 운동을 실시한 결과 능동 운동에서만 공간인식의 긍정적인 회복 을 보고하였고 Eskes 등 ${ }^{28}$ 의 연구에서도 능동 운동을 통하여 무시공 간의 주의력과 마비측의 근 수축 증진을 보고하였다. 이는 기존에 적 용된 치료방법 중에서 수동적인 치료접근보다는 능동운동을 통한 치료접근이 편측무시 환자의 공간인식 및 신체기능 향상에 도움이 될 수 있음을 시사한다.

20 명의 환자를 대상으로 진행한 본 연구는 진행한 중재를 통하여 두치료군의 두점구별, 입체인식, 자세조절과 보행의 회복에 도움을 주었다. 이는 기존의 다양한 치료접근을 통하여 편측무시를 동반한 편마비 환자의 감각구별, 지각, 자세조절 및 보행증진에 도움을 줄 수 있으며 기존치료에 추가적으로 진행된 상지 체감각 훈련은 감각을 보다 집중화하여 증진하는 차별화된 접근방법으로 설명할 수 있을 것이다. 연구결과, 두치료군의 두점구별의 신체부위 변화에서 보존 적 치료군에서는 두점구별의 아래팔 부위에서, 체감각 훈련군에서 는 모든 부위에서 두점구별능력이 증가하였고 두 치료군 간의 두점 구별, 입체인식에서 차이를 확인할 수 있었다. 이는 손을 포함하는 상 지는 다른 신체 부위와 다르게 많은 수용기의 지배 영역과 밀집도가 크며 발달된 체감각 수용기의 자극은 시상을 경유, 중추 신경의 체감 각 피질까지 정보를 전달하여 신체인식 및 자세 조절에 관련한 정보 를 제공하는데 강력한 차별성을 갖는다고 할 수 있다.29 따라서 이를 기반으로 진행한 상지 체감각 훈련은 기존치료에 추가하여 감각을 집중화하여 감각기능을 증진하며 편측무시 환자의 손상된 신체인식 력을 회복하는 데 있어차별화된 치료접근이라고 사료된다.

그리고 본 연구에서는 보존적 치료군과 체감각 훈련군 사이에 PASS와 CTSIB를 통해 자세조절의 특성을 알아보고자 하였는데 이 중 정적인 선 자세 자세조절능력을 알아보고자 사용된 CTSIB 검사 중 바닥면의 변화 없이 시각정보를 제공한 자세조절검사에서 두 치 료군 사에서 차이가 있음을 확인할 수 있었다. 편측무시를 동반한 편 마비 환자는 정상인에 비해 시각정보를 이용하여 신체를 조절하거나 기능활동을 수행하는 높은 시각 의존도를 가진다. 정상인의 경우 단 단한 바닥면에서 선 자세를 유지하는 데 있어 시각정보 $10 \%$, 전정감 각 $20 \%$ 및 체감각 정보 70\%를 사용하는 반면 편마비 환자는 70\% 이상 의 시각정보를 사용하여 선 자세를 유지하려고 한다. ${ }^{30}$ 이러한 과도한 시각정보의 의존은 선 자세의 비효율성을 증가시켜 자세유지 및 보 행을 더욱 어렵게 한다. 또한 뇌졸중 후 편마비 환자는 1 차적으로 마 
비측 하지와 체간의 항중력 기능 저하로 어깨주위의 해부학적인 정 렬, 생역학적 특성, 신체인식력 및 역동적인 자세조절에도 부정적인 영향을 미친다. ${ }^{31,32}$ 이는 편마비 환자의 역동적인 자세조절 향상을 위 하여 어깨 주위의 근력과 체간의 항중력 기능 및 신체인식증진을 훈 련이 병행되어야 함을 시사한다. 따라서 CTSIB 중 LDEO에서의 변화 는 상지 체감각 훈련을 통하여 시각의존도를 감소시키고 선 자세의 항중력 요소를 개선하여 체중심 이동의 효율성을 증가시켰을 것으 로 사료된다.

뇌졸중 후 편마비 환자의 자세조절 향상에 있어 근약화의 증진과 비정상적인 자세 긴장도를 정상화시키는 치료과정과 더불어 신체 내 의 수많은 구심성 감각 정보를 통합하고 이를 통해 공간 내에서 신체 를 인식하는 능력을 향상하도록 치료하는 것이 중요하다. 특히 손에 제공되는 체감각 정보는 선 자세에서 신체 요동을 최소화하는 데 도 움을 주는데 이는 손의 접촉면에 제공되는 감각 정보를 통하여 공간 내 신체 위치를 인식하는 도움요소로 작용하여 시각정보를 적게 사 용하고 신체 요동에 대하여 적절한 반응하는데 도움을 줄 수 있을 것 이다. ${ }^{33,34}$

또한 본 연구는 뇌졸중 후 편측무시를 동반한 편마비 환자에게 적 용한 상지 체감각 훈련이 인간보행에 어떠한 도움이 되는지를 알아 보고자 하였고 연구결과, 두 치료군 모두에게 치료 전, 후에서 보행증 진에 도움을 주었으나 두 치료군 간의 차이를 확인할 수 없었다.

뇌졸중 후 편마비 환자의 큰 특징 중 하나는 자세 조절과 보행 능 력의 저하로 일상생활의 범위를 제한하는 것이다. ${ }^{14}$ 따라서 뇌졸중 발 병 후 편마비 환자의 독립적이고 효율적인 보행은 재활과정에서 중요 한 치료목표가 된다. ${ }^{3}$ 인간의 기능적인 보행을 위해서는 하지의 관절 정렬 상태와 고관절 외전근을 포함한 하지의 항중력근 역할이 필수 적이며 이중 편마비 환자의 보행능력에 영향에 주는 항중력근의 효 율적인 활동을 위해서는 골반과 대퇴부 그리고 대퇴부 사이의 정상 적인 정렬이 수반되어야 한다. ${ }^{35}$ 하지만 편마비 환자의 보행증진은 항 중력근 기능증진뿐만 아니라 상지와 어깨주위 근 활동의 개선을 통 한 선 자세의 효과적인 정렬과 조절력을 증진하여 보다 효율적인 보 행을 수행할 수 있다.

본 연구에서 시행한 두치료군의 치료 전후 TUG 검사에서 보존적 치료군에서는 치료 전 63.62초에서 치료 후 56.55초로 향상되었고 체 감각 치료군에서는 치료전 57.11초에서 치료 후 39.24초로 보존적 치 료군에 비해 보행 소요시간에 차이가 있음을 알 수 있다. 비록 두 치료 군 간의 TUG 검사에서 유의한 차이를 보이지 않았지만 체감각 치료 군이 보존적 치료군에 비해 정상인의 보행 소요시간에 근접하고 있 음을 알 수 있었다. 일반적으로 60대 정상 남성의 TUG 소용 시간은 연 구자와 대상에 따라 다르나 평균 8-13.1초로 알려져 있으며 신경학적 손상이 없는 정상인에서는 10 초 미만 소요되는 것으로 조사되었고 ${ }^{16}$
대부분의 선행연구에서 보행속도가 빨라지면 TUG도 빨라지고 자세 조절이 좋아질수록 보행속도와 TUG가 빨라진다고 보고하였다.14

따라서 추가된 상지 체감각 훈련은, 선 자세의 효과적인 정렬과 조 절력 증진과 보행속도에 영향을 주어 보행의 효율성에 영향을 줄 수 있을 것으로 사료되며 이는 편마비 환자의 마비측 어깨뼈 주위근의 등척성 운동을 통하여 어깨뼈의 정렬 변화되어 선 자세에서 체중부 하 지지율, 분배에 변화 및 동적 서기 균형 및 보행증진에 도움을 준 다는 선행 연구를 통해 설명할 수 있을 것이다. ${ }^{36,37}$ 따라서 본 연구에 서 진행한 두 치료군의 6 주간의 물리작업치료와 추가된 상지 체감각 훈련 모두 편마비 환자의 보행 회복에 긍정적으로 작용하였고 특히 상지 체감각 훈련을 포함한 물리작업치료는 환자의 자세조절 및 보 행을 증진에 적용할 수 있는 치료접근이라 사료된다.

본 연구의 제한점으로는 상지 체감각 훈련 외의 치료 내용과 치료 에 영향을 주는 환경 변수를 통제하기 어려웠으며 적용 환자의 수가 적어 이를 일반화하여 해석하는 데 어려움이 있을 것으로 사료된다.

\section{ACKNOWLEDGEMENTS}

This study was supported by 2014 Research Grant from Kangwon National University (No. 220140137).

\section{REFERENCES}

1. Shumway-Cook A, Woollacott MA. Motor control translating research into clinical practice. 3rded. Baltimore, Lippincott William \& Wilkins, 2007:299-309.

2. Inman VT. Human Locomotion. Can Med Assoc J. 1966;94(14):104754.

3. Kim JH.Relationship between gait symmetry and functional balance, walking performance in subjects with stroke. J Kor Phys Ther. 2014; 26(1):1-8.

4. Patla AE. Neurobiomechanical base for the control of human locomotion. In: Bronstein A, Brandt T, Woollacott M, eds. Balance posture and gait. Arnold. London, 1996:19-40.

5. Karnath HO, Rennig J, Johannsen L et al. The anatomy underlying acute versus chronic spatial neglect: A longitudinal study. Brain. 2011;134(1): 903-12.

6. Karnath HO, Rorden C. The anatomy of spatial neglect. Neuropsychologia. 2012;50(1):1010-7.

7. Kerkhoff G, Schenk T. Rehabilitation of neglect: An update. Neuropsychologia. 2012;50(1):1072-9.

8. Ladavas E, Bonifazi S, Catena L et al. Neglect rehabilitation by prism adaptation: Different procedures have different impacts. Neuropsychologia. 2011;49(5):1136-45.

9. Tsang MH, Sze KH, Fong KN. Occupational therapy treatment with right half-field eye-patching for patients with subacute stroke and unilateral neglect: A randomised controlled trial. Disabil Rehabil. 2009;31(1): 
630-7.

10. Borchers S, Hauser TK, Himmelbach M. Bilateral hand representations in human primary proprioceptive areas. Neuropsychologia. 2011;49(1): 3383-91.

11. Morch CD, Andersen OK, Quevedo AS et al. Exteroceptive aspects of nociception: Insights from graphesthesia and two-point discrimination. Pain. 2010;342(3):187-90.

12. Julkunen L, Tenovuo O, Jäskeläinen SK et al. Recovery of somatosensory deficits in acute stroke. Acta Neurol Scand. 2005;111(1):366-72.

13. Hwang BY. Effects of proprioceptive control program on the balance and walking in the persons with chronic stroke. Keimyung University. Dissertation of Doctorate Degree. 2002.

14. Benaim C, Pérennou DA, Villy J et al. Validation of a standardized assessment of postural control in stroke patients: The Postural Assessment Scale for Stroke Patients (PASS). Stroke. 1999;30(1):1862-8.

15. Podsiadlo D, Richardson S. The timed up \& go: A test of basic functional mobility for trail elderly persons. J Am Geriatr Soc. 1991;39(1):142-8.

16. Morris S. Morris ME, Iansek R. Reliability of measurements obtained with the times up and go test in people with parkinson disease. Phys Ther, 2001;83(2):810-8.

17. Song BK. Effect of somatosensory stimulation on upper limb in sensory, hand function, postural control and ADLs within sensorimotor deficits after stroke. J Kor Phys Ther. 2012;24(5):291-9.

18. Jung MS, Park JW. The relationship between balance test and fear of falling in community dwelling elderly. J Kor Phys Ther. 2012;24(1):23-8.

19. Park SK, Kang YH. Effects of weight distribution and balance with foot orthotics in hemiplegic patients. J Kor Phys Ther. 2012;24(3):241-6.

20. Utz KS, Keller I, Artinger F et al. Multimodal and multispatial deficits of verticality perception in hemispatial neglect. Neuroscience. 2011;188(1): 68-9.

21. Ladavas E, Berti A, Ruozzi E et al. Neglect as a deficit determined by an imbalance between multiple spatial representations. Exp Brain Res. 1997;16(3):493-500

22. Petersen SE, Posner MI. The attention system of the human brain: 20 years after. Annu Rev Neurosci. 2012;35(1):73-89.

23. Ptak R, Schnider A. The attention network of the human brain: Relating structural damage associated with spatial neglect to functional imaging correlates of spatial attention. Neuropsychologia. 2011;49(11):3063-70.
24. Kinsbourne M. Mechanisms of unilateral neglect. In: Jeannerod M, eds. Neurophysiological and neuropsychological aspects of spatial neglect. Amsterdam, North-Holland, 1987:69-86.

25. Zoltan B, Siev E. Freishtat B. The adult stroke patient a manual for evaluation and treatment of perceptual and cognitive dysfunction reversed 2nd ed. Thorofare, Slack, 1991:51-70.

26. Coslett HB. Evidence for a disturbance of the body schema in neglect. Brain Cogn. 1998;37(3):527-44.

27. Robert IH, North N. Active and passive activation of left limb: Influence on visual and sensory neglect. Neuropsychologia.1993;31(3):293-300.

28. Eskes GA, butler B, Mcdonald A. Limb activation effects in hemispatial neglect. Arch Phys Med Rehabil. 2003;84(1):323-8.

29. Kim JH. Effect of Visual feedback training on standing-balance in stroke with neglect and sensory deficit. Daegu University. Dissertation of Doctorate Degree. 2007.

30. Balslev D, Odoj B, Karnath, HO. Role of somatosensory cortex in visuospatial attention. J Neurosci. 2013;33(46):18311-8.

31. Dickstein R, Shefi S, Marcovitz E et al. Anticipatory postural adjustment in selected trunk muscles in poststroke hemiparetic patients. Arch Phys Med Rehabil. 2004;85(1):261-7.

32. Peterka RJ. Sensorimotor integration in human postural control. J Neuphy. 2002;88(1):1097-18.

33. Baldan AMS, Alouche SR, Araujo IMG et al. Effect of light touch on postural sway in individuals with balance problems: A systematic review. Gait \& Posture 40(1), 2014;1-10.

34. Kirker SGB, Simpson DS, Jenner JR et al. Stepping before standing: Hip muscle function in stepping and standing balance after stroke. J Neurol Neurosurg Psychiatry. 2000;68(1):458-64.

35. Martinelli AR, Coelho DB, Magalhaes FH et al. Light touch modulates balance recovery following perturbation from fast response to stance restabilization. Exp Brain Res. 2015;233(5):1399-408.

36. Chang J, Lee S, Lee M et al. The correlations between gait speed and muscle activation or foot pressure in stroke patients. J Kor Soc Phys Ther. 2009;21(3):47-52.

37. Kim GH, Choe HS, Lee HI et al. The effects of scapular stabilization exercising on dynamic standing balance in stroke patients. J Kor Phys Ther. 2014;26(1):15-20. 